\title{
Predictors of Non-Utilization of the Supplemental Nutrition Program for Women, Infants, and Children (WIC) in San Francisco, CA 2008-2011
}

\author{
Pegah Faed ${ }^{1,2}$, Jodi Stookey ${ }^{2}$, Michael Batech ${ }^{1,3}$, Arelene Blix ${ }^{1}$, and Serena Tonstad ${ }^{1}$ \\ ${ }^{1}$ Loma Linda University, School of Public Health \\ ${ }^{2}$ San Francisco Department of Public Health, MCAH Department \\ ${ }^{3}$ Loma Linda University, Center for Health Research
}

\begin{abstract}
Background and Purpose: Non-utilization of nutrition-related services is high, especially among women who are at high risk of outcomes such as low birth weight. We investigated predictors of nonutilization of the Supplemental Nutrition Program for Women, Infants and Children (WIC) during 20082011 in San Francisco, California. Methods: Using California Birth Cohort Files, we identified 35,295 singleton births from 2008-2011; 25,884 did not use WIC services. Results: Major findings from Classification and Regression Tree (CRT) analysis were: 1) the strongest predictor of WIC non-utilization was no insurance; 2) $97.3 \%$ of the private insurance/self-pay population did not utilize WIC and of this population, non-Hispanic whites, Hispanics, and Asian/Pacific Islanders, with some college or more, and fathers with some college or more were least likely to utilize WIC services. Medi-Cal insurance coverage was protective against non-use of WIC, while maternal or paternal completion of at least some college. Non-Hispanic white ethnicity and maternal or paternal age of 35 years or older were predictors of nonutilization of WIC. Conclusions: Sociodemographic variables and insurance status were predictive of WIC non-utilization, suggesting groups that may be targeted in efforts to increase WIC uptake. Current efforts for targeting traditionally underserved populations should continue, while adding additional efforts to serve other women from traditionally advantaged backgrounds who meet the eligibility requirements for WIC.
\end{abstract}

(C) 2014 Californian Journal of Health Promotion. All rights reserved. Keywords: WIC; adverse infant outcomes; health disparities; city and county of San Francisco; perinatal epidemiology

\section{Introduction}

In 2010, the Centers for Disease Control and Prevention (CDC) reported an annual incidence of low birth weight of $8.2 \%$ in the United States, with a majority of state-specific incidences ranging from $7.0 \%$ to $9.0 \%$ (CDC, 2011). In California, the annual incidence of low birth weight across counties ranges from $4.9 \%$ to 7.8\% (California Department of Public Health, 2011). The incidence of low birth weight in the City and County of San Francisco has remained stable, between $6.4 \%$ to $7.4 \%$ between 2000 and 2010, despite improvement in control and prevention strategies, including access to the Supplemental Nutrition program for Women, Infants, and Children (WIC) (California
Department of Public Health (CDPH), 2011). Black infants are more likely than infants of all other races to be born with low birth weight (Hamilton, Martin, \& Ventura, 2012). Maternal tobacco use, insufficient weight gain during pregnancy, low education level and maternal age (younger than 18 and older than 35) have all been found to increase risk of low birth weight (Goldenberg \& Culhane, 2007). Low birth weight has been reduced through mothers' increased utilization of Medicaid coverage for prenatal care, and also increased utilization of WIC (Kistka, 2007; Lu \& Halfon, 2003).

\section{Prenatal Interventions}

Interventions that improve prenatal nutrition and decrease prenatal smoking, substance abuse, 
chronic stress, and medical problems can limit the adverse effects of socioeconomic factors on low birth weight (Aber \& Bennett, 1997). Public policy at the federal level has the best chance to improve adverse birth outcomes, such as low birth weight. Early Head Start, and Women, Infants, and Children (WIC) are examples of programs that have received federal funding for its existence. However, poor birth outcomes continue to exist, in particularly vulnerable subpopulations such as low income and African American populations (Blumenshine \& Egerter, 2010).

\section{Supplemental Nutrition Program for Women, Infants, and Children (WIC)}

The Supplemental Nutrition Program for Women, Infants, and Children (WIC) is a free program locally available throughout the United States that provides financial assistance to states to serve pregnant women with an income at or below $185 \%$ of the federal poverty line or who are determined to be at nutritional risk by a health care professional. WIC services provide supplemental nutrient-rich foods that are scientifically-selected for infants and children up to age five who are found to be a nutritional risk, health care referrals for enrolled women and their children, and nutrition and health education for low-income pregnant women (Ripple \& Zigler, 2003).

\section{WIC Participation}

According to a study conducted on WIC participation in North Carolina, women who received Medicaid benefits and prenatal WIC services had significantly lower rates of low and very low birth weight than did women who received Medicaid but not prenatal WIC (Buescher, Larson, Nelson, \& Lenihan, 1993). It is estimated that for each $\$ 1.00$ spent on WIC services, Medicaid cost-savings for newborn medical care was \$2.91 (Buescher et al., 1993). Among white women who utilized WIC services, low birth weight rates were $22 \%$ lower than those who did not utilize WIC; among black women, rates with 31\% lower than those who did not utilize WIC (Buescher et al., 1993). Non-Hispanic black women who participated in WIC and received early prenatal care had lower rates of low birth weight deliveries, more similar to the city-wide average (Buescher et al., 1993). However, neither WIC nor Medicaid alone replicates these findings (Buescher et al., 1993). This difference in outcomes may be attributed to the programs themselves or a selection bias, but it is important to identify whether there is a systematic problem or a loophole of eligibility criteria (i.e., WIC qualifications). Examining the sociodemographic characteristics of women not utilizing WIC services could provide a foundation for efforts to reach out to underserved segments of the population and hopefully improve birth outcomes throughout San Francisco.

A twenty-year review of the effects of the WIC program showed a higher mean birth weight among women who participated in WIC in comparison to those who were eligible but did not participate (Owen \& Owen, 1997; Richards, Merrill et al., 2011). The mechanism by which WIC helps improve birth outcomes is through maternal nutrition supplementation, nutrition education, women's health care supervision, and assistance to utilize various social services. The extra attention placed on these low-income women who, under normal circumstances, would not receive any of these services, makes a lasting difference in their own health and the health of their infants (Owen \& Owen, 1997).

\section{Eligibility}

The literature has minimal information regarding characteristics of women utilizing or not utilizing WIC. However, a recent Morbidity and Mortality Weekly Report examined eligibility and enrollment in WIC within 27 states and New York City from 2007 to 2008. The findings indicated that historically advantaged backgrounds who WIC eligible do not utilize the services. Of all the women surveyed, approximately $17 \%$ were eligible but not enrolled in WIC during pregnancy. NonHispanic white women who were eligible nonparticipants were $57 \%$ of the eligible nonparticipant population. About 44\% of eligible nonparticipants had some college or more; $40.8 \%$ of eligible nonparticipants had private insurance; and $47.4 \%$ of eligible nonparticipants had normal pre-pregnancy BMI (CDC, 2013). 


\begin{abstract}
Aims
With San Francisco being an extremely diverse city, focusing our study on this population makes the findings generalizable to various populations and settings. The aim of this paper was to better understand the sociodemographic characteristics of women not utilizing WIC services and to elucidate the segments of the population least likely to use WIC among mothers that gave birth in San Francisco between 2008-2011. Our specific aims were: 1) to identify specific subpopulations at increased risk for WIC non-utilization by examining the combination of these predictors using classification and regression tree (CRT) analysis; 2) to examine individual modifiable and non-modifiable determinants of WIC nonutilization.
\end{abstract}

\section{Methods}

\section{Study Design}

This retrospective cohort study utilized a Birth Statistical Master File collected for all singleton live births to registered residents in San Francisco, California from 2008 through 2011. Approval for this study was obtained through the Institutional Review Board at Loma Linda University, and the City and County of San Francisco Health Officer.

\section{Sample}

Between 2008-2011, 35,295 total live births were registered in San Francisco, 25,884 of which did not utilize WIC. Cases with missing data were excluded. The analysis was not restricted to Medi-Cal only women because there may be uninsured or privately insured women who are also eligible for WIC services. Excluding all other payer options could skew the results.

\section{Data Collection of Predictor Variables}

California state law requires birth certificates to be completed for all births at the hospital relatively soon after birth (CDC, 2013). In conjunction with each participating state, the National Center for Health Statistics developed protocol guidelines to standardize the data collection process across all facilities $(\mathrm{CDPH}$,
2011). Standardized protocols for data collection include two worksheets: a Mother's Worksheet and a Facility Worksheet. Maternal and paternal characteristics are collected using the Mother's Worksheet and include race/ethnicity, education, smoking status, and WIC participation status. The Facility Worksheet collects data directly from the facility medical records for the mother and newborn, and includes birth weight, method of delivery, and complications of pregnancy and delivery such as gestational diabetes and preeclampsia diagnosis (CDPH, 2011).

We examined the following non-modifiable predictors: maternal and paternal age $(<18,18-$ 35 , and $>35$ years), maternal race/ethnicity (nonHispanic white, non-Hispanic black, Hispanic, Asian/Pacific Islander, or other/multirace/unknown), maternal and paternal education ( $<$ high school, high school diploma, some college or more), parity ( $<3$ live births, 3 live births or more), and surrogate measures of socioeconomic status that included the primary payer for prenatal care. Modifiable predictors included were maternal tobacco use status (never smoker, smoking during pregnancy, prepregnancy smoker only), and pre-pregnancy BMI (underweight, normal, overweight, obese). Some variables available on the birth certificate were not included in the analysis because those health outcomes exist temporally after WIC services would have been utilized (i.e. birth complications, post-pregnancy weight).

\section{Outcome Measures}

The outcome of interest was non-utilization of WIC services during pregnancy and was measured as a dichotomous variable.

\section{Analysis}

To check for at risk groups that might be defined by multiple or combined predictors, we used a CRT analysis. The methodology was formalized by Brieman et al. (1984) and is a multivariate statistical model that develops classification systems, which predict or classify future observations based on a set of decision rules. These systems identify subgroups of individuals at highest risk of a particular outcome without a priori assumptions. The algorithms examine all the fields within the dataset to identify the one 
that gives the best classification or prediction by splitting the data into subgroups. The process is applied recursively, splitting subgroups into smaller and smaller units until the tree is finished as defined by the stopping criteria. In principle, splitting of the decision tree could continue until all cases are classified or predicted. However, this would not be very useful or accurate for future predictions. Therefore, the default stopping criteria involves setting a minimum sample size to stop classifying. Default settings and stopping rules were used for this CRT analysis. The target and input fields used in tree building can be continuous or categorical, depending on the algorithm used. Based on this methodology, the process will automatically include only the attributes which are important in making a decision. Attributes that do not contribute to the accuracy of the tree are excluded. This can yield important information about the data and can be used to reduce the data to relevant fields. Insurance status was forced as the first node because it was the strongest predictor of WIC non-utilization.

To identify heterogeneous subpopulations, we used a Two'ing impurity measure criteria with a minimum change in improvement criteria of 0.0001. The Two'ing impurity is a measure of how often a randomly chosen element from the set would be incorrectly labeled if it were randomly labeled according to the distribution of labels (Breiman et al., 1983). Univariate analyses were conducted on the each of the nonmodifiable and modifiable risk factor examined to assess normality and to test the assumptions for multivariate logistic regression. These included Mantel-Haenszel Chi-square comparing levels of each risk factor by WIC non-utilization status and the KolmogorovSmirnov test for normality.

The CRT analysis predicted the combined effects of multiple predictors. we also examined the association between each individual predictor and WIC non-utilization using multivariate logistic regression. The logistic regression model contained the same predictor variables as the CRT analyses. Logistic regression was done to determine what barriers may exist in accessing WIC services. This analysis is ideal for hypothesis testing while the CRT analysis is beneficial for hypothesis generation.

\section{Results}

Table 1 presents the frequencies and percentages of each of the modifiable and non-modifiable determinants of WIC utilization status. Of the 35,295 participants, $73.3 \%$ did not utilize WIC services. We found that a majority of women who did not use WIC services had less than 3 live births and a substantial portion of all women who did not utilize WIC services were never smokers, gained "too little" weight, had some college or more, were 35 years or older, were non-Hispanic whites, had private insurance, or more than 10 prenatal visits.

Figure 1 provides the results of CRT analysis for WIC non-utilization. Insurance status was forced to be the first node because it was the strongest predictor of WIC non-utilization. Four subpopulations resulted from this forced split: 1) Non-Hispanic white mothers with Medi-Cal or other insurance; 2) all other race/ethnicities with Medi-Cal or other insurance coverage; 3) mothers with some college or more who had private or no insurance; and 4) mothers with a high school diploma or less than high school education with private or no insurance. In the first subpopulation, non-Hispanic white women were less likely to utilize WIC services and WIC non-utilization was more likely among mothers with some college or more and even more likely for obese or overweight mothers with Medi-Cal. Women of Asian/Pacific Islander descent with other insurance coverage and some college education or more were less likely to utilize WIC services than their non-Hispanic Black or Hispanic counterparts. 


\section{Table 1}

Demographic Characteristics of Mothers by WIC Utilization in San Francisco County (2008-2011)

\begin{tabular}{|c|c|c|c|c|}
\hline & $\begin{array}{c}\text { Total } \\
(\mathrm{N}=35,295)\end{array}$ & $\begin{array}{c}\text { WIC Non- } \\
\text { Utilization } \\
(n=25,884)\end{array}$ & $\begin{array}{l}\text { WIC Utilization } \\
\qquad(\mathrm{n}=9,411)\end{array}$ & p-value \\
\hline & n (column \%) & n (column \%) & n (column \%) & \\
\hline \multicolumn{5}{|l|}{ Modifiable Determinants } \\
\hline \multicolumn{5}{|l|}{ Maternal Tobacco Use } \\
\hline Never Smoker & 34,607 (98.1) & $25,563(98.8)$ & $9,044(96.2)$ & $<0.01$ \\
\hline Smoking During Pregnancy & $473(1.3)$ & $178(0.7)$ & $295(3.1)$ & \\
\hline Pre-pregnancy Smoker Only & $186(0.5)$ & $127(0.5)$ & $59(0.6)$ & \\
\hline \multicolumn{5}{|l|}{ Pre-Pregnancy Body Mass Index } \\
\hline Mean (Std. Dev.) & $23.5(6.0)$ & $22.7(4.4)$ & $25.6(8.6)$ & $<0.01$ \\
\hline Underweight (12.0-18.50) & $1,590(4.5)$ & $1,142(6.2)$ & 448 (6.5) & $<0.01$ \\
\hline Normal (18.50-24.99) & $16,793(47.6)$ & $13,563(73.4)$ & $3,230(47.0)$ & \\
\hline Overweight (25.0-29.9) & $4,454(12.6)$ & $2,637(14.3)$ & $1,817(26.4)$ & \\
\hline Obese $(30.0+)$ & $2,520(7.1)$ & $1,135(6.1)$ & $1,385(20.1)$ & \\
\hline \multicolumn{5}{|l|}{ IOM Qualitative Weight Gain } \\
\hline Too Little & $29,148(82.6)$ & $21,585(90.0)$ & 7,563 (83.2) & $<0.01$ \\
\hline Just Right & $3,324(9.4)$ & $2,100(8.8)$ & $1,224(13.5)$ & \\
\hline Too Much & $603(1.7)$ & 299 (1.3) & $304(3.3)$ & \\
\hline \multicolumn{5}{|l|}{ Non-Modifiable Determinants } \\
\hline \multicolumn{5}{|l|}{ Parity } \\
\hline Less than 3 live births & $33,776(95.7)$ & $25,289(97.7)$ & $8,487(90.2)$ & $<0.01$ \\
\hline 3 or more live births & $1,514(4.3)$ & $590(2.3)$ & $924(9.8)$ & \\
\hline \multicolumn{5}{|l|}{ Maternal Age } \\
\hline$<18$ Years & $336(1.0)$ & $69(0.3)$ & $267(2.8)$ & $<0.01$ \\
\hline $18-<35$ Years & $22,358(63.3)$ & $14,766(57.1)$ & $7,592(80.7)$ & \\
\hline 35 Years or older & $12,595(35.7)$ & $11,044(42.7)$ & $1,551(16.5)$ & \\
\hline \multicolumn{5}{|l|}{ Maternal Race/Ethnicity } \\
\hline Non-Hispanic white & $14,147(40.1)$ & $13,584(52.5)$ & $563(6.0)$ & $<0.01$ \\
\hline Non-Hispanic black & $1,917(5.4)$ & $746(2.9)$ & $1,171(12.4)$ & \\
\hline Hispanic & $7,206(20.4)$ & $2,522(9.7)$ & $4,684(49.8)$ & \\
\hline Asian/Pacific Islander & $10,430(29.6)$ & $7,812(30.2)$ & $2,618(27.8)$ & \\
\hline Other/Multi/Unknown & $1,595(4.5)$ & $1,220(4.7)$ & $375(4.0)$ & \\
\hline \multicolumn{5}{|l|}{ Mother's Highest Education } \\
\hline Less than High School Diploma & $4,210(11.9)$ & $509(2.0)$ & $3,701(40.0)$ & $<0.01$ \\
\hline High School Diploma & $4,937(14.0)$ & $2,001(7.9)$ & $2,936(31.7)$ & \\
\hline Some College or More & $25,599(72.5)$ & $22,982(90.2)$ & 2,617 (28.3) & \\
\hline \multicolumn{5}{|l|}{ Paternal Age } \\
\hline$<18$ Years & $99(0.3)$ & $23(0.1)$ & $76(0.9)$ & $<0.01$ \\
\hline $18-<35$ Years & $16,130(45.7)$ & $10,412(41.2)$ & $5,718(68.5)$ & \\
\hline 35 Years or older & $17,377(49.2)$ & $14,826(58.7)$ & $2,551(30.6)$ & \\
\hline \multicolumn{5}{|l|}{ Father's Highest Education } \\
\hline Less than High School D. & $3,780(10.7)$ & 464 (1.9) & $3,316(41.1)$ & $<0.01$ \\
\hline High School Diploma & $5,422(15.4)$ & $2,557(10.3)$ & $2,865(35.5)$ & \\
\hline Some College or More & $23,645(67.0)$ & $21,759(87.8)$ & $1,886(23.4)$ & \\
\hline \multicolumn{5}{|c|}{ Principal Source of Payment for Prenatal Care } \\
\hline Self-Pay & $570(1.6)$ & $524(2.0)$ & $46(0.5)$ & $<0.01$ \\
\hline Private Insurance & $24,308(68.9)$ & $23,671(91.5)$ & $637(6.8)$ & \\
\hline Medi-Cal & $9,642(27.3)$ & $1,407(5.4)$ & $8,235(87.5)$ & \\
\hline Other & $775(2.2)$ & $282(1.1)$ & $493(5.2)$ & \\
\hline
\end{tabular}




\section{Table 2}

Age- and Multivariate-adjusted Odds Ratios for Selected Demographic Features of Mothers in San Francisco County for WIC Non-utilization in San Francisco County (2008-2011)

\begin{tabular}{|c|c|c|}
\hline $\mathrm{N}=35,524$ & $\begin{array}{l}\text { Age-Adjusted } \\
\text { AOR }(95 \% \mathrm{CI})\end{array}$ & $\begin{array}{c}\text { Multivariate Adjusted }^{1} \\
\text { AOR (95\% CI) }\end{array}$ \\
\hline $\begin{array}{l}\text { Modifiable Predictors } \\
\text { Maternal Tobacco Use } \\
\text { Never Smoker } \\
\text { Smoking During Pregnancy } \\
\text { Pre-pregnancy Smoker } \\
\text { Only } \\
\text { Pre-Pregnancy Body Mass Index } \\
\text { Underweight (12.0-18.50) } \\
\text { Normal (18.50-24.99) } \\
\text { Overweight (25.0-29.9) } \\
\text { Obese }(30.0+)\end{array}$ & $\begin{array}{l}0.64(0.57,0.72) \\
1.00 \text { (Reference) } \\
0.35(0.33,0.38) \\
0.20(0.18,0.22)\end{array}$ & $\begin{array}{l}0.89(0.70,1.14) \\
1.00 \text { (Reference) } \\
0.67(0.56,0.79) \\
0.54(0.44,0.66)\end{array}$ \\
\hline $\begin{array}{l}\text { Non-Modifiable Predictors } \\
\text { Parity } \\
\text { Less than } 3 \text { live births } \\
3 \text { or more live births }\end{array}$ & $\begin{array}{l}1.00 \text { (Reference) } \\
0.16(0.14,0.18)\end{array}$ & $\begin{array}{l}1.00 \text { (Reference) } \\
0.85(0.65,1.12)\end{array}$ \\
\hline $\begin{array}{l}\text { Maternal Age } \\
\quad<18 \text { Years } \\
18-<35 \text { Years } \\
35 \text { Years or older }\end{array}$ & $\begin{array}{l}0.13(0.10,0.17) \\
1.00 \text { (Reference) } \\
3.66(3.45,3.89)\end{array}$ & $\begin{array}{l}1.09(0.55,2.18) \\
1.00 \text { (Reference) } \\
1.36(1.15,1.61)\end{array}$ \\
\hline $\begin{array}{l}\text { Mother's Race/Ethnicity } \\
\text { Non-Hispanic white } \\
\text { Non-Hispanic black } \\
\text { Hispanic } \\
\text { Asian/Pacific Islander } \\
\text { Other/Multi/Unknown }\end{array}$ & $\begin{array}{l}1.00 \text { (Reference) } \\
0.03(0.03,0.04) \\
0.03(0.02,0.03) \\
0.13(0.12,0.15) \\
0.15(0.13,0.17)\end{array}$ & $\begin{array}{l}1.00 \text { (Reference) } \\
0.14(0.11,0.19) \\
0.15(0.12,0.18) \\
0.22(0.18,0.26) \\
0.43(0.31,0.60)\end{array}$ \\
\hline $\begin{array}{l}\text { Mother's Education } \\
\text { Less than High School D. } \\
\text { High School Diploma } \\
\text { Some College or More }\end{array}$ & $\begin{array}{c}0.19(0.17,0.21) \\
1.00 \text { (Reference) } \\
11.40(10.62,12.24)\end{array}$ & $\begin{array}{l}0.67(0.53,0.85) \\
1.00 \text { (Reference) } \\
1.98(1.68,2.33)\end{array}$ \\
\hline $\begin{array}{l}\text { Father's Age } \\
\quad<18 \text { Years } \\
18-<35 \text { Years } \\
35 \text { Years or older }\end{array}$ & $\begin{array}{l}2.32(1.37,3.93) \\
1.00 \text { (Reference) } \\
2.28(2.12,2.44)\end{array}$ & $\begin{array}{l}2.61 \text { (0.98, 6.98) } \\
1.00 \text { (Reference) } \\
1.43(1.23,1.65)\end{array}$ \\
\hline $\begin{array}{l}\text { Father's Education } \\
\text { Less than High School D. } \\
\text { High School Diploma } \\
\text { Some College or More } \\
\text { Principal Source of Payment for } \\
\text { Prenatal Care } \\
\text { Self-Pay } \\
\text { Private Insurance } \\
\text { Medi-Cal } \\
\text { Other }\end{array}$ & $\begin{array}{l}0.31(0.23,0.43) \\
1.00 \text { (Reference) } \\
0.01(0.01,0.01) \\
0.02(0.01,0.02)\end{array}$ & $\begin{array}{l}0.26(0.16,0.42) \\
1.00 \text { (Reference) } \\
0.01(0.01,0.01) \\
0.03(0.03,0.05)\end{array}$ \\
\hline
\end{tabular}

1 - Multivariate model includes all other covariates listed in this table.

Of the subpopulation of the private insured or self-payers, all racial/ethnic groups with some college education or more were less likely to use WIC services. Non-Hispanic black and Hispanic women who were normal weight, underweight, or overweight pre-pregnancy were the least likely to utilize WIC services in this population. Hispanic, Asian/Pacific-Islander, and NonHispanic black women with a high school diploma and more than 10 prenatal visits were less likely to utilize WIC services than their nonHispanic white counterparts. 
Table 2 presents the multivariate adjusted logistic regression odds ratios with 95\% confidence interval limits for each risk factor as a predictor of WIC non-utilization outcome in San Francisco from 2008 to 2011. The strongest relationship was seen when examining insurance status. Compared to the reference category of private insurance, the effects of Medi-Cal status was highly protective against WIC nonutilization. High parity and pre-pregnancy smoking were only statistically significant for age-adjusted logistic regression results of WIC non-utilization, and may be indicating a correlation between the two variables which needs to be further investigated. Parity and tobacco use may be flagging the same individuals in relation to WIC non-utilization. We found that, compared to those with a high school diploma, women with some college education were significantly less likely to utilize WIC services. Non-Hispanic white women were found to be least likely to utilize WIC services.

\section{Discussion}

This study aimed to identify populations not participating in WIC. The study found that sociodemographic factors, Medi-Cal insurance status, and high parental education are possible flags for WIC non-utilization. Previous research in this field is limited.

\section{Insurance Status}

The strong association between insurance status and WIC non-use is likely due to the type of individuals usually referred to WIC. WIC enrollment eligibility criteria are fairly broad and increasing awareness of these criteria could help increase WIC utilization. We noted a substantial proportion of women with private insurance or who self-pay, non-Hispanic whites, and those with at least some college were less likely to utilize WIC services (more than $97 \%$ of privately insured or uninsured mothers did not use WIC). Most of these cases may not be financially eligible for WIC in the first place.

Another possible issue that may exist is regarding a systems issue of enrollment into WIC services. While Medi-Cal may have special enrollment relationships with WIC, those women eligible for WIC but are privately covered or uninsured may not enroll for the services they need due to inadequacies in the system created to funnel participants into WIC. The data used for this analysis does not include sufficient information to determine this and may be an important approach for future research. The results indicate that one mode of outreach may be through insurance companies to help increase awareness of WIC services and eligibility.

Based on previous research conducted on low birth weight determinants in the same population of San Francisco births from 2008 to 2011, WIC utilization was found to be protective against low birth weight outcomes. We found that among women who gave birth to low birth weight babies, 73\% did not utilize WIC services (unpublished findings). Non-Hispanic white women, women with some college or more, and women with private insurance comprised large portions of those delivering low birth weight births. These findings indicate that the populations found to be at higher risk of not utilizing WIC are suffering from adverse birth outcomes as well (Faed et al., unpublished).

\section{Age}

Compared to women between the ages of 18 and 34 , women 35 years or older were significantly more likely to not utilize WIC services than their younger counterparts. This relationship could be attributed to the fact that older women tend to be more financially stable and are not eligible for WIC services or they do need these services and are eligible, but are unaware due to poor outreach to this population.

\section{Eligibility}

It is important to acknowledge the issue of eligibility and enrollment in WIC services. As indicated in the Morbidity and Mortality Report, approximately $17 \%$ of women surveyed were eligible but not enrolled in WIC during pregnancy. Of those women, the characteristics match those identified in this study as those who do not utilize WIC services. These findings support the need to targeting those found to not access WIC but are eligible. In this particular 
study, it remains unclear what percentage of these women are eligible for WIC and just not participating. This relationship needs further investigation.

Both the logistic regression and CRT analyses found similar predictors for WIC non-utilization. Maternal tobacco non-use and normal prepregnancy BMI were two modifiable predictors that were significantly associated with nonutilization of WIC. However, it is important to acknowledge that changing tobacco use may not change WIC use. It is a correlation that may be useful for identifying outreach populations but may not be a causal relationship. Improving awareness and access to programs that will reduce maternal tobacco use and nutritionally monitor the health of women of childbearing age can improve birth outcomes. Programs such as WIC have been found to be protective against poor birth outcomes and all the modifiable predictors mentioned are addressed during program participation (Buescher et al., 1993).

\section{Limitations}

To our knowledge, these are the first countywide WIC non-utilization outcome findings by birth weight from the City and County of San Francisco, as well as the first use of California state birth certificates for this purpose. The model included data for all mothers and may not have been sensitive to small but high risk groups, such as Pacific Islanders. The model rules were a limitation of the analysis as well. With the CRT analysis allowing four branches for each tree, the results were limited to the four most important subgroups. Additionally, we had limited capacity to examine interactions and subgroups in our logistic regression model. The models dropped records with missing data for the variable used in the split. It remains to be determined how the groups with missing data would be classified.

The results and conclusions of this study are limited due to the information available on each birth from the birth certificate data. Maternal and paternal alcohol and drug use information was not available. Income level was also unavailable, but we did use surrogate measures of socioeconomic status. Other unavailable information that would likely be important for this analysis includes poverty, homelessness, trauma, domestic violence, chronic stress, lack of social support, neighborhood pollution, and crime. It is important to note that the birth files for 2008 to 2011 were combined and since identifiers had been removed, some mothers who delivered twice during those years may have been included twice. Alcohol and drug use information were not available for these participants. Income level was also unavailable, limiting the findings of this study. Other unavailable variables or not included but important to the model were homelessness, presence of diabetes, and no interest in being assessed. This analysis excluded health predictors, such as asthma, infection, and chlamydia, that are available on the birth certificate and might serve as flags for intervention, but relatively rare.

The analysis did not include year or crossvalidation. Therefore, the analysis assumes constant risk over time. It remains to be confirmed that the resulting classifications predict risk over time. Additionally, the results may underestimate the prevalence of maternal smoking status since underreporting of tobacco use is higher among pregnant smokers than nonpregnant smokers

\section{Conclusions}

Our study examined several modifiable and nonmodifiable predictors of non-utilization of WIC services and used them to identify specific populations at increased risk of non-utilization in San Francisco. The goal was not to compare the methods but rather investigate overall risk and sub-group risk utilizing both analyses. Both logistic regression and classification trees found similar predictors for LBW in previous studies. The results need to be confirmed in a validation sample.

Using these findings, public health prevention efforts geared towards improving the burden of adverse birth outcomes can target the identified high-risk populations to improve WIC utilization, which is shown to improve birth outcomes. It is critical for programs, like WIC, to conduct more outreach to the populations 
identified. While these populations may be identified as in need for WIC services but not utilizing them, they are also typically wellserved populations with positive health outcomes. It is apparent from these findings that they, too, are at some degree of risk for poor birth outcomes. Targeted interventions can help improve those efforts to reduce adverse infant outcomes in specific subpopulations of identified in this study.

\section{References}

Aber, J. L., \& Bennett, N. G. (1997). The effects of poverty on child health and development. Annual Review of Public Health, 18, 463-483.

Alexander, G. R., Fau - Korenbrot, C. C. \& Korenbrot, C. C. (1996). The role of prenatal care in preventing low birth weight. The Future of Children, 15, 1054-8289.

Blumenshine, P., Egerter, S., Barclay C., Cubbin, C., \& Braveman, P. (2010). Socioeconomic Disparities in Adverse Birth Outcomes: A Systematic Review. American Journal of Preventive Medicine, 39(3), 263-272.

Breiman, L., Friedman, J. H., Olshen, R. A., \& Stone, C. J. (1984). Classification and regression trees. New York; CRC Press.

Buescher, P. A., Larson, L. C., Nelson, M. D., \& Lenihan, A. J. (1993) Prenatal WIC participation can reduce low birth weight and newborn medical costs: a cost-benefit analysis of WIC participation in North Carolina. Journal of the American Dietetic Association, 93(2), 163-166.

Centers for Disease Control, Health Disparities and Inequalities Report. (2011). Retrieved from http://www.cdc.gov/minorityhealth/reports/CHDIR11/FactSheet.pdf

Centers for Disease Control, National Center for Health Statistics. (2012, May 25). Retrieved from http://www.cdc.gov/nchs/births.htm

Centers for Disease Control, Morbidity and Mortality Weekly Report (MMWR) (2013, March 15). Retrieved from http://www.cdc.gov/mmwr/preview/mmwrhtml/mm6210a3.htm\#tab2

Cheng, D., Branscum, A., \& Johnson, W. (2012). Sample size calculations for ROC studies: parametric robustness and Bayesian nonparametrics. Statistics in Medicine, 31(2), 131-42.

Hamilton, B. E., Martin, J. A., \& Ventura, S. J. (2012). Births: Preliminary data for 2011. National Vital Statistics Reports, 61(5). Hyattsville, MD: National Center for Health Statistics. Available at: http://www.cdc.gov/nchs/data/nvsr/nvsr61/nvsr61_05.pdf

Deming, D. (2009). Early childhood intervention and life-cycle skill development: evidence from head start. American Economic Journal: Applied Economics, 1(3), 111-134.

Goldenberg, R. L., \& Culhane, J. F. (2007). Low birth weight in the United States. American Journal of Clinical Nutrition, 85(2), 584S-590S.

Hanley, J. A., \& McNeil, B. J. (1983). A Method of Comparing the Areas under Receiver Operating Characteristic Curves Derived from the Same Cases. Radiology, 148, 839-843.

Kraemer, H. C. (1992). Evaluating Medical Tests. Newbury Park; Sage Publications.

Hosler, A. S., Nayak, S. G., \& Radigan, A.M. (2011). Stressful events, smoking exposure and other maternal risk factors associated with gestational diabetes mellitus. Paediatric and Perinatal Epidemiology, 25(6), 566-574.

Janevic, T., \& Stein, C. R. (2010). Neighborhood Deprivation and Adverse Birth Outcomes among Diverse Ethnic Groups. Annals of Epidemiology, 20(6), 445-451.

Kiernan, M., Kraemer, H. C., Winkleby, M. A., King, A. C., \& Taylor, C. B. (2001). Do logistic regression and signal detection identify different subgroups at risk? Implications for the design of tailored interventions. Psychological Methods, 6(1), 35-48.

Lu, M. C., \& Halfon, N. (2003). Racial and ethnic disparities in birth outcomes: A life-course perspective. Maternal and Child Health Journal, 7(1), 13-30.

Martin, J. A., Hamilton, B.E., Sutton, P.D., Ventura, S.J., Menacker, F., Kirmeyer, S., \& Munson, M.L. (2007). Births: final data for 2005. National Vital Statistics Reports, 56(6), 1-89.

Owen, A. L., \& Owen, G. M. (1997). Twenty years of WIC: A review of some effects of the program. Journal of the American Dietetic Association, 97(7), 777-782. 
Richards, R., R., Merrill, M., Baksh, L., \& McGarry, J. (2011). Maternal health behaviors and infant health outcomes among homeless mothers: U.S. Special Supplemental Nutrition Program for Women, Infants, and Children (WIC) 2000. Preventive Medicine, 52(1), 87-94.

Ripple, C. H., \& Zigler, E. (2003). Research, policy and the federal role in prevention initiatives for children. American Psychologist, 58(6/7), 482-490.

U.S. Department of Health and Human Services. (2004). The health consequences of smoking: A report of the surgeon general, 2004. Washington, DC: U.S. Government Printing Office.

\author{
Author Information \\ *Pegah Faed ${ }^{1,2}$ DrPH, MPH \\ pfaed@llu.edu, pegah.faed@gmail.com \\ Health Equity Fellow ${ }^{2}$ \\ $14307^{\text {th }}$ Street, \#505 \\ Santa Monica, CA 90401 \\ (925) 395-7169 \\ Jodi Stookey ${ }^{2}, \mathrm{PhD}$ \\ jstookey@sfdph.org \\ Senior Epidemiologist ${ }^{2}$ \\ Michael Batech ${ }^{1,3}$, MPH \\ mbatech@llu.edu \\ Research Analyst ${ }^{3}$ \\ Arelene Blix ${ }^{1}$, DrPH, RN \\ ablix0@gmail.com \\ Emeritus Professor ${ }^{1}$ \\ Serena Tonstad ${ }^{1}$, MD, PhD, MPH \\ stonstad@llu.edu \\ Professor, Dept. of Health Promotion and Education ${ }^{1}$ \\ 1 - Loma Linda University, School of Public Health \\ 24951 North Circle Drive \\ Nichol Hall 1703 \\ Loma Linda, CA 92350 \\ 2 - San Francisco Department of Public Health, MCAH \\ Department \\ 30 Van Ness Ave, Suite 200 \\ San Francisco, CA 94102 \\ 3 - Loma Linda University, Center for Health Research \\ 24951 North Circle Drive \\ Nichol Hall 1517 \\ Loma Linda, CA 92350 \\ * corresponding author
}

